\title{
Avaliação do Índice de Remanescente Adesivo utilizando braquetes com e sem tratamento na base e a interação com três sistemas de colagem
}

\author{
Lilian Maria Brisque Pignatta*, Isabel Cristina Prado Torres Lugato**, Francisco Antonio Bertoz ${ }^{\star \star \star}$,

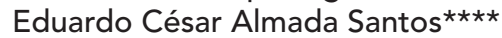

\begin{abstract}
Resumo
Objetivo: avaliar o Índice de Remanescente Adesivo (IRA) em dentes bovinos após a descolagem de braquetes com e sem tratamento na base. Metodologia: foram utilizados três sistemas de colagem ortodôntica para os dois padrões de base. Os dentes bovinos foram divididos em seis grupos de 40, de acordo com a base do braquete e o sistema de colagem. Vinte e quatro horas após a colagem foram realizados os testes de compressão em uma máquina de ensaios. A avaliação do IRA foi realizada em um estereomicroscópio por três examinadores calibrados. Foi utilizado o teste não paramétrico de Kruskal-Wallis, seguido do método de Dunn, para fazer as comparações múltiplas entre todos os grupos. Resultados e Conclusões: observou-se que o tratamento das bases dos braquetes com óxido de alumínio não foi determinante para o aumento da adesividade entre o braquete e o adesivo. $\mathrm{O}$ grupo em que se utilizou braquetes com tratamento na base e adesivo TXT (3M-Unitek) + Transbond Plus SEP (3M-Unitek) apresentou a maior parte das fraturas na interface dente-adesivo (escore 4).
\end{abstract}

Palavras-chave: Ortodontia. Esmalte dentário. Adesivos.

\section{INTRODUÇÃO}

Com o advento da técnica do condicionamento ácido, por Buonocore ${ }^{7}$, ocorreu uma considerável evolução na Odontologia. Esse fato também permitiu avanços tecnológicos na Ortodontia, pois, associada à melhoria das propriedades dos sistemas resinosos, a colagem direta de braquetes passou a ser o procedimento de escolha ${ }^{24}$.

Sadler ${ }^{25}$, em 1958, publicou o primeiro artigo sobre a técnica de colagem direta de braquetes ortodônticos sobre a superfície do esmalte dentário sem a necessidade de bandagem em todos os dentes. Isto promoveu um aumento no número de estudos envolvendo materiais de colagem biologicamente compatíveis ao meio bucal e que garantam maior estabilidade dente-adesivo-braquete ${ }^{2,8}$.

O objetivo é obter-se um material de colagem com força de união suficiente entre dente, resina e braquete para suportar as cargas mastigatórias, as forças ortodônticas e os fluidos do meio bucal ${ }^{19}$.

\footnotetext{
* Doutoranda em Ortodontia pela Faculdade de Odontologia de Araçatuba - UNESP. Mestre e especialista em Ortodontia pela Faculdade de Odontologia de Araçatuba - UNESP.

** Mestre em Ortodontia pela Faculdade de Odontologia de Araçatuba - UNESP.

*** Professor titular da disciplina de Ortodontia do Departamento de Odontologia Infantil e Social da Faculdade de Odontologia de Araçatuba UNESP. Professor do programa de pós-graduação em Ortodontia da Faculdade de Odontologia de Araçatuba - UNESP.

**** Professor adjunto da disciplina de Ortodontia do departamento de Odontologia Infantil e Social da Faculdade de Odontologia de Araçatuba UNESP. Professor do programa de pós-graduação em Ortodontia da Faculdade de Odontologia de Araçatuba - UNESP.
} 
Porém, grande importância deve ser dada à preservação da superfície do esmalte ao término do tratamento ortodôntico, mantendo o mesmo grau de rugosidade ou lisura de um dente não tratado ${ }^{11}$.

Com a introdução da colagem direta, evidenciou-se também uma preocupação com a relação entre os braquetes e as forças de adesão adequadas. Keizer, Ten Cate e Arends ${ }^{12}$, ao estudarem a união dente-resina-braquete, observaram que o local da fratura, responsável pela queda dos braquetes, ocorria normalmente na interface resinabraquete.

Desde então, busca-se uma forma de aumentar a adesão braquete-resina ${ }^{14,17,26,27}$. Modificações já foram introduzidas nos braquetes metálicos, tanto na redução de seu tamanho quanto alterações em sua base ${ }^{16}$, consideradas variáveis que influenciam diretamente na permanência intacta da superfície fragilizada. Uma dessas modificações constitui-se no pré-tratamento das bases com jateamento ${ }^{16,18}$, silanização ${ }^{18}$, aplicação de camada de sílica ${ }^{18}$, mi- $^{-}$ cro-condicionamento ${ }^{16}$ ou aplicação de promotores de adesão ${ }^{18}$.

Encontram-se disponíveis no mercado braquetes com bases tratadas industrialmente visando esta melhoria da retenção ${ }^{9}$. Porém, esse aumento na adesividade não apresenta um consenso na literatura $^{9,10}$.

Para avaliação dos sistemas de colagem, podem ser realizados testes mecânicos - como ensaios de compressão ou tração -, reproduzindo as falhas de adesão que ocorrem mais freqüentemente na clínica $^{8}$; verificação da superfície do esmalte com microscopia eletrônica de varredura ${ }^{20}$; análise do comportamento dos materiais por meio de estudos clínicos longitudinais; e a utilização do Índice de Remanescente Adesivo (IRA) 1,3,5,22,29.

Pelo IRA pode-se avaliar os locais onde ocorreram as falhas na adesão e quantificar o remanescente adesivo que permanece no dente e/ou braquete $^{1}$. É um sistema que permite a análise estatística e comparações com outros estudos, facilitando a padronização dos testes de força de ade- são in vitro ${ }^{1,22}$. A fragilidade da ligação na adesão pode estar na superfície do dente, no braquete ou dentro das camadas do adesivo. As fraturas adesivas ocorrem na interface adesivo-braquete ou adesivo-esmalte e as fraturas coesivas ocorrem no interior do material adesivo ${ }^{22,23}$.

Diante do exposto, objetiva-se avaliar o Índice de Remanescente Adesivo em dentes bovinos utilizando braquetes com e sem tratamento na base e três sistemas de colagem ortodôntica.

\section{MATERIAL E MÉTODOS}

Para o estudo in vitro foram utilizados 240 incisivos permanentes bovinos, armazenados em solução aquosa de Timol a 0,1\%, para inibir o crescimento bacteriano em temperatura ambiente ${ }^{21}$. Foram selecionados apenas dentes intactos tanto na superfície vestibular como lingual, sem trincas causadas pela pressão do extrator e/ou fórceps. Para verificar a existência de trincas no esmalte foi realizada a transiluminação da face vestibular dos dentes com luz de fibra óptica ${ }^{30}$.

Os acessórios utilizados para a colagem foram 120 braquetes de aço inoxidável para incisivo central superior (Kirium line - Abzil, São José do Rio Preto/SP, Brasil) com bases em malha convencional e 120 braquetes de aço inoxidável para incisivo central superior (Kirium line - Abzil) com bases em malha fina pré-tratadas industrialmente com jateamento de óxido de alumínio. A superfície média da base dos braquetes foi de $13 \mathrm{~mm}^{2}$, como determinado pelo fabricante.

Os três sistemas de colagem ortodôntica utilizados foram: sistema $\mathrm{A}$ - kit adesivo Transbond ${ }^{\mathrm{TM}} \mathrm{XT}$ convencional (3M - Unitek, St. Paul, Mn, EUA); sistema B - adesivo autocondicionante Transbon$\mathrm{d}^{\mathrm{TM}}$ Plus Self Etching Primer com resina fotopolimerizável Transbond ${ }^{\mathrm{TM}}$ XT (3M - Unitek, St. Paul, $\mathrm{Mn}, \mathrm{EUA})$; e sistema C - cimento de ionômero de vidro resinoso Fuji Ortho LC em cápsulas (GC Corp., Tokyo, Japan). O protocolo de colagem para cada sistema está especificado no quadro 1.

Os espécimes foram divididos em seis grupos 


\begin{tabular}{|c|c|c|c|}
\hline $\begin{array}{c}\text { 3M - Unitek, St. Paul, } \\
\text { Mn, EUA }\end{array}$ & $\begin{array}{c}\text { Transbond } \mathrm{d}^{\mathrm{TM}} \text { Light Cure } \\
\text { adhesive Primer (3M- } \\
\text { Unitek) } \\
\text { Lote: } 4 \mathrm{BP} \\
\text { Validade: } 03 / 07\end{array}$ & $\begin{array}{l}\text { Primer; Trietilenoglicol-dimetacri- } \\
\text { lato, Bis-GMA }\end{array}$ & $\begin{array}{l}\text { SISTEMA-A } \\
\text { 1) Aplicou-se, na superfície mais plana e vestibular da } \\
\text { coroa dentária, ácido fosfórico gel a } 35 \% \text { por } 15 \text { se- } \\
\text { gundos, lavou-se com seringa tríplice por } 15 \text { segundos, } \\
\text { secou-se com jato de ar comprimido por } 15 \text { segundos; } \\
\text { 2) Aplicou-se uma camada fina e uniforme de Transbon- } \\
\text { dTM XT Adesivo-Primer (3M-Unitek) na superfície dentá- }_{\text {ria que iria receber o braquete por } 3 \text { segundos com pon- }} \text { tas de pincel descartáveis e dissolveu-se com um ligeiro } \\
\text { jato de ar isento de umidade; } \\
\text { 3) Aplicou-se com a seringa uma pequena quantidade } \\
\text { da pasta adesiva Transbond }{ }^{\mathrm{TM}} \text { XT (3M-Unitek) na base } \\
\text { do braquete e, imediatamente após a aplicação do ade- } \\
\text { sivo, posicionou-se o braquete na superfície preparada } \\
\text { do dente; } \\
\text { 4) Ajustou-se o braquete na posição final, pressionando- } \\
\text { o firmemente por } 10 \text { segundos, retirou-se os excessos } \\
\text { cuidadosamente com uma sonda exploradora; } \\
\text { 5) A polimerização foi feita com um fotopolimerizador do } \\
\text { tipo Ultralux (Dabi Atlante, Indústria Médico Odontológi- } \\
\text { ca, Ribeirão Preto/SP, Brasil) e potencial radiométrico de } \\
500 m W / c m^{2} \text { (miliWatts por centímetro quadrado), duran- } \\
\text { te vinte segundos fazendo o feixe de luz incidir por dez } \\
\text { segundos em cada lado mesial e distal e aproximada- } \\
\text { mente } 5 \mathrm{~mm} \text { acima do contato proximal. }\end{array}$ \\
\hline $\begin{array}{c}\text { 3M - Unitek, St. Paul, } \\
\text { Mn, EUA }\end{array}$ & $\begin{array}{c}\text { Pasta adesiva } \\
\text { Transbond }{ }^{\mathrm{TM}} \mathrm{XT} \\
\text { (3M-Unitek) } \\
\text { TXT } \\
\text { Lote: } 4 \mathrm{kh} \\
\text { Validade: } 03 / 07 \\
\text { Transbond }{ }^{\mathrm{TM}} \text { Plus } \\
\text { Self Etching Primer } \\
\text { (3M- Unitek) } \\
\text { TXT SEP } \\
\text { Lote: } 206494 \\
\text { Validade: } 10 / 06\end{array}$ & $\begin{array}{l}\text { Mono e di-hema-fosfato, } \\
\text { canforoquinona, água destilada, } \\
\text { aminobenzoato, hexafluortitanato } \\
\text { de potássio, butilhidróxitolueno, } \\
\text { metilparabeno e propilparabeno }\end{array}$ & $\begin{array}{l}\text { SISTEMA - B } \\
\text { Este sistema de colagem é igual ao Sistema A, com ex- } \\
\text { ceção dos itens } 1 \text { e 2, que são substituídos por um único } \\
\text { passo, aplicação do Transbond Plus SEP (3M Unitek) } \\
\text { adesivo-primer autocondicionante. Importante salien- } \\
\text { tar que este material foi aplicado no esmalte após a } \\
\text { profilaxia, lavagem e secagem com leve jato de ar para } \\
\text { remover o excesso de água, em campo úmido, por } 3 \text { se- } \\
\text { gundos, seguido de um leve jato de ar, como recomenda } \\
\text { o fabricante. }\end{array}$ \\
\hline $\begin{array}{l}\text { GC Corp., Tokyo, } \\
\text { Japan }\end{array}$ & $\begin{array}{l}\text { Fuji Ortho LC em cápsulas } \\
\text { (GC Corp.) Cimento de } \\
\text { ionômero de vidro resinoso } \\
\text { (CIVR-FO/LC) } \\
\text { Lote: } 412101 \\
\text { Validade:12/06 }\end{array}$ & $\begin{array}{l}\text { Grãos de flúor-alumínio de silicato } \\
\text { de vidro, ácido poliacrílico, água, } \\
\text { três monômeros de resina e dois } \\
\text { hidroximetilmetacrilato (HEMA) }\end{array}$ & $\begin{array}{l}\text { SISTEMA - C } \\
\text { 1) Aplicou-se o ácido poliacrílico a } 11,5 \% \text { por } 20 \text { segun- } \\
\text { dos na superfície do esmalte, lavou-se por } 10 \text { segundos, } \\
\text { seguido de jato de ar por } 10 \text { segundos e umideceu-se a } \\
\text { superfície com água; } \\
\text { 2) Aglutinou-se as cápsulas com ionômero de vidro re- } \\
\text { sinoso em um amalgamador Ultramat } 2 \text { SDT (Bayswater, } \\
\text { Victoria, Austrália) com vibrações em alta velocidade } \\
\text { por } 10 \text { segundos; } \\
\text { 3) Removeu-se as cápsulas do amalgamador e colocou- } \\
\text { as em um aplicador GC Fuji Capsule Aplier; } \\
\text { 4) Acomodou-se a mistura na base do braquete e este } \\
\text { aderiu-se ao esmalte dentário firmemente; } \\
\text { 5) Polimerização por } 40 \text { segundos, } 10 \text { segundos de cada } \\
\text { lado, mesial, distal, cervical e incisal com potencial ra- } \\
\text { diométrico de } 500 \mathrm{~mW} / \mathrm{cm}^{2} \text {. }\end{array}$ \\
\hline
\end{tabular}

\section{Quadro 1 - Protocolo dos sistemas de colagem.}

de quarenta dentes, segundo o tipo de base do braquete e o material de colagem utilizado. A distribuição da amostra pode ser observada no quadro 2.

Após a colagem dos acessórios ortodônticos, os espécimes foram mantidos em água deionizada por um período de 24 horas. O teste destrutivo foi realizado numa Máquina Universal de Ensaios DL 3000 (EMIC, São José dos Pinhais/PR, Brasil) utilizando célula de carga de 200Kgf (quilogramaforça) e velocidade de $1 \mathrm{~mm} / \mathrm{min}$ em direção gengivo-incisal. 
Posteriormente à descolagem dos braquetes, os grupos foram examinados após uma semana em um estereomicroscópio Technival 2 (Carl Zeiss, Zena, Alemanha) com aumento de $25 x$ por três examinadores calibrados (Exl, Ex2 e Ex3) para avaliar o local da falha adesiva e a presença de adesivo residual. Os espécimes foram codificados e os examinadores não tinham conhecimento de qual material estava sendo avaliado no momento da observação. Utilizando a porcentagem de resina aderida ao esmalte, os escores do Índice de Remanescente Adesivo (IRA) descrito por Bishara e Trulove 4 foram avaliados em cada espécime: escore 1 - todo adesivo no dente, escore 2 - mais de $90 \%$ de adesivo no dente, escore 3 - mais de $10 \%$ e menos de $90 \%$ de adesivo no dente, escore 4 - menos de 10\% de adesivo no dente, escore 5 nenhum adesivo no dente.

\section{ANÁLISE ESTATÍSTICA}

Para determinar as diferenças estatísticas entre os grupos após a descolagem, foi utilizado o teste não-paramétrico de Kruskal-Wallis, seguido do método de Dunn, para fazer as comparações dos grupos experimentais. Verificou-se a concordância entre os examinadores utilizando o índice de kappa (k), cuja interpretação, segundo Landis e $K_{\text {Koch }}{ }^{13}$, está demonstrada no quadro 3.

\section{RESULTADOS}

Observou-se que o nível de concordância para o teste interexaminadores obteve um índice de kappa com valores considerados de substancial a quase perfeito (Tab. 1). Os resultados obtidos pelos examinadores foram avaliados pela freqüência dos dados segundo o Índice de Remanescente Adesivo (IRA) determinado por Bishara e Trulove ${ }^{4}$.

O teste de Kruskal-Wallis (Tab. 2) revelou que houve diferença estatisticamente significante entre os grupos $(\mathrm{p}<0,001)$. O método de Dunn (Tab. 3) verificou que o grupo 4 teve diferença estatística significante em $5 \%$ entre o grupo 1 e o

\begin{tabular}{cccl} 
grupos & espécimes & $\begin{array}{c}\text { jateamento da base } \\
\text { do braquete }\end{array}$ & material de colagem \\
\hline 1 & 40 & não & $\begin{array}{l}\text { TXT convencional } \\
\text { TXT convencional }\end{array}$ \\
\hline 2 & 40 & sim & $\begin{array}{l}\text { TXT + Transbond } \\
\text { Plus SEP }\end{array}$ \\
\hline 4 & 40 & não & $\begin{array}{l}\text { TXT + Transbond } \\
\text { Plus SEP }\end{array}$ \\
\hline 5 & 40 & sim & CIVR-cap. \\
Fũo & Furtho LC \\
\hline 6 & 40 & sivR-cap. & Fuji Ortho LC
\end{tabular}

Quadro 2 - Apresentação dos grupos de estudo de acordo com os tipos de bases de braquetes e sistemas de colagem.

$\begin{array}{ll}\text { kappa } & \text { interpretação } \\ <0,00 & \text { pobre } \\ 0 \text { a } 0,20 & \text { fraca } \\ 0,21 \text { a } 0,40 & \text { razoável } \\ 0,41 \text { a } 0,60 & \text { moderada } \\ 0,61 \text { a } 0,80 & \text { substancial } \\ 0,81 \text { a } 0,99 & \text { quase perfeita }\end{array}$

Quadro 3 - Interpretação da concordância obtida pelo valor de kappa.

Tabela 1 - Protocolo dos sistemas de colagem.

\begin{tabular}{|lll}
\hline examinadores & estatística kappa & interpretação \\
\hline Ex1 X Ex2 & 0,87 & quase perfeita \\
\hline Ex1 X Ex3 & 0,80 & substancial \\
Ex3 X Ex2 & 0,81 & quase perfeita \\
\hline
\end{tabular}

Tabela 2 - Determinação das diferenças estatísticas entre os grupos após a descolagem pelo teste de Kruskal-Wallis.

\begin{tabular}{ccc} 
grupo & soma dos pontos & espécimes \\
1 & 3509,0 & 40 \\
2 & 5444,0 & 40 \\
3 & 5078,5 & 40 \\
4 & 5444,0 & 40 \\
5 & 4788,5 & 40 \\
6 & 4137,0 & 40 \\
\hline
\end{tabular}

$\mathrm{p}=0,0003$.

$\mathrm{H}=23,54788$ (significante em $0,1 \%$ ). 
Tabela 3 - Comparações dos grupos experimentais pelo método de Dunn.

\begin{tabular}{ccccc} 
comparações & diferença & $\mathbf{p}$ & $\mathbf{0}$ & significância \\
\hline $2 \times 1$ & 48,375 & 5 & 3,341 & $*$ \\
\hline $2 \times 3$ & 9,137 & 2 & 0,631 & n.s. \\
$2 \times 4$ & 12,975 & 2 & 0,896 & n.s. \\
\hline $2 \times 5$ & 16,387 & 3 & 1,132 & n.s. \\
$2 \times 6$ & 32,675 & 4 & 2,257 & n.s. \\
$3 \times 1$ & 39,238 & 4 & 2,710 & n.s. \\
$3 \times 4$ & 22,112 & 3 & 1,527 & n.s. \\
\hline $3 \times 5$ & 7,250 & 2 & 0,501 & n.s. \\
\hline $3 \times 6$ & 23,538 & 3 & 1,626 & n.s. \\
\hline $4 \times 1$ & 61,350 & 6 & 4,237 & $*$ \\
\hline $4 \times 5$ & 29,362 & 4 & 2,028 & n.s. \\
\hline $4 \times 6$ & 45,650 & 5 & 3,153 & $*$ \\
\hline $5 \times 1$ & 31,988 & 3 & 2,209 & n.s. \\
\hline $5 \times 6$ & 16,288 & 2 & 1,125 & n.s. \\
\hline $6 \times 1$ & 15,700 & 2 & 1,084 & n.s. \\
\hline
\end{tabular}

* Significante em 5\%; n.s. = não significante; $p=$ probabilidade; 0 = distribuição de probabilidade.

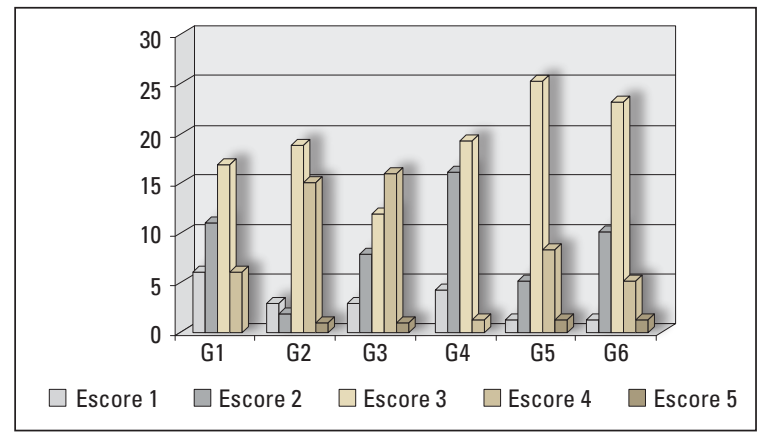

GRÁFICO 1 - Quantidade de espécimes com adesivo residual de acordo com 0 Índice de Remanescente Adesivo (IRA) para os sistemas adesivos e as bases dos braquetes com e sem tratamento.

grupo 6. Também houve diferença entre o grupo 2 e grupo 1.

Na gráfico 1, os resultados do IRA para o grupo 1 demonstraram um maior número de espécimes entre os escores 3 e 2. Os grupos 2, 3 e 4 se apresentaram entre os escores 3 e 4 . Para os grupos 5 e 6 , a maior porcentagem de espécimes apresentouse no escore 3.

\section{DISCUSSÃO}

A colagem direta de braquetes ortodônticos tem melhorado a prática clínica na Ortodontia. Constantes modificações são feitas nos materiais de colagem ${ }^{2,8}$ e nas bases dos braquetes ${ }^{16,28}$ para aumentar as forças de adesão visando à otimização dos resultados e o ganho de tempo clínico.

Contudo, o aumento da adesão dificulta a remoção dos acessórios no término do tratamento, podendo ocasionar trincas e fraturas na superfície dentária ${ }^{3,29}$; e o que se almeja é a preservação do esmalte o mais próximo de seu estado original, com mínima perda durante a colagem, descolagem e polimento coronário ${ }^{11}$.

Para isso, as fraturas na interface braqueteadesivo ou no interior do adesivo, permanecendo o material de colagem aderido ao dente, são favoráveis para evitar prejuízos ao esmalte, pois o resíduo pode ser removido com instrumentos rotatórios adequados, de forma mais segura ${ }^{3,15,29}$.

Pela sua objetividade e praticidade na forma de analisar, considera-se eficaz o IRA proposto por Bishara e Trulove 4 quando o objetivo é a avaliação dos sistemas de colagem por meio da verificação do local da falha de união e da quantidade de adesivo remanescente aderido no dente e braquete.

Os resultados da estatística de kappa para a verificação do nível de concordância entre os examinadores foi de substancial a quase perfeito, denotando a fidedignidade do método de avaliação pelo IRA.

O teste de Kruskal-Wallis demonstrou que existem pelo menos dois grupos diferentes entre si e o método de Dunn, ao realizar comparações entre os grupos, verificou que o grupo 4 (braquetes com bases tratadas e sistema de colagem TXT, 3M-Unitek + Transbond Plus SEP, 3M-Unitek) diferiu do grupo 1 (braquetes sem tratamento nas bases e sistema de colagem TXT, 3M-Unitek) e do grupo 6 (braquetes com bases tratadas e sistema de colagem Fuji Ortho LC, GC Corp.), pois permaneceu mais adesivo no braquete, sugerindo uma fraca adesividade do material de colagem ao 
dente ou maior retenção ao braquete.

Houve também diferenças estatisticamente significantes entre o grupo 2 (braquetes bases tratadas e sistema de colagem TXT, 3M-Unitek) e o grupo 1 (braquetes sem tratamento nas bases e sistema de colagem TXT, 3M-Unitek), demonstrando haver maior retenção na malha do braquete com jateamento de óxido de alumínio quando utilizou-se o mesmo material de colagem.

No grupo 1, observou-se escores $3(42,5 \%)$ e 2 $(27,5 \%)$, corroborando os resultados encontrados por Bishara et al. ${ }^{5,6}$, Owens Jr. e Miller ${ }^{22}$, que verificaram a tendência de permanecer mais adesivo aderido ao dente em relação à base do braquete.

Nos grupos 2 e 4, em que as bases dos braquetes foram tratadas com óxido de alumínio, o IRA revelou que a falha adesiva ocorreu com maior freqüência na interface dente-adesivo, pois os escores para estes grupos foram 3 e 4 .

O grupo 3 - colado com TXT (3M-Unitek) + Transbond Plus SEP (3M-Unitek) com braquetes sem bases tratadas - apresentou 40\% dos espécimes no escore 4 e 30\% no escore 3 , sugerindo neste estudo uma menor adesividade do material de colagem ao dente, o que diferiu dos resultados encontrados por Bishara et al. ${ }^{5}$, que se apresentaram predominantemente no escore 3 .

Nos grupos 5 e 6, que utilizaram o material de colagem Fuji Ortho LC (GC Corp.), não foram observadas diferenças na falha de união em relação às bases dos braquetes com e sem tratamento, pois ambos obtiveram escore 3 , denotando a ausência de tendência do remanescente adesivo permanecer, em sua maior parte, no dente ou no braquete. Yamada, Hayakawa e Kasai ${ }^{29}$ observaram que a utilização desse material para a colagem de braquetes sem bases tratadas resultou em uma falha de união na interface dente-adesivo, opondo-se também aos resultados de Owens Jr. e Miller ${ }^{22}$, em que a falha ocorreu na interface braquete-adesivo.

\section{CONCLUSÃO}

O tratamento das bases dos braquetes com óxido de alumínio não foi determinante para o aumento da adesividade entre o braquete e o adesivo.

O grupo TXT (3M - Unitek) + Transbond Plus SEP (3M - Unitek) e braquetes com bases tratadas apresentou a fratura na interface dente-adesivo, ou seja, maior prevalência de material de colagem aderido ao braquete (escore 4 ).

\title{
Evaluation of Adhesive Remnant Index using conventional mesh bases and sandblasted orthodontic bracket bases and three bonding systems
}

\begin{abstract}
Aim: To assess the Adhesive Remnant Index (ARI) in bovine teeth after debonding mesh bases and sandblasted orthodontic bracket bases. Methods: Were used three bonding systems for the two standards of base. The bovine teeth were divided into 6 groups of 40 , according to the bracket base and to the bonding system. Twenty four hours after bonding they had been carried through shear bond strength tests in a universal testing machine. The assessment of ARI was performed in a stereomicroscopy by three calibrated examiners. It was used the non-parametric Kruskall-Wallis test, followed by Dunn's method, to do the multiple comparisons among all groups. Results and conclusions: It was observed that the aluminum oxide sandblasting bracket bases was not determinative to the increase of the adhesiveness between bracket and adhesive. The group where it was used sandblasted orthodontic bracket bases and bonding system TXT (3M-Unitek) + Transbond Plus SEP (3M-Unitek) presented the majority of the failures at the teeth-adhesive interface (score 4).
\end{abstract}

Key words: Orthodontics. Dental enamel. Adhesives. 


\section{REFERÊNCIAS}

1. ÅRTUN, J.; BERGLAND, S. Clinical trials with crystal growth conditioning as an alternative to acid-etch enamel pretreatment. Am. J. Orthod., St. Louis, v. 85, no. 4, p. 333-340, Apr. 1984

2. BISHARA, S. E.; AJLOUNI, R.; LAFFOON, J. F.; WARREN, J. $J$. Effects of modifying the adhesive composition on the bond strength of orthodontic brackets. Angle Orthod., Appleton, v. 72, no. 5, p. 464-467, 2002.

3. BISHARA, S. E.; OLSEN, M. E.; VonWALD, L.; JAKOBSEN, J. R. Comparison of the debonding characteristics of two innovative ceramic bracket designs. Am. J. Orthod. Dentofacial Orthop., St. Louis, v. 116, no. 1, p. 86-92, July 1999.

4. BISHARA, S. E.; TRULOVE, T. S. Comparisons of different debonding techniques for ceramic brackets: an in vitro study. Part II: findings and clinical implications. Am. J. Orthod. Dentofacial Orthop., St. Louis, v. 98, no. 3, p. 263-273, Sept. 1990.

5. BISHARA, S. E.; VonWALD, L.; LAFFOON, J. F.; WARREN, J. J. Effect of a self-etch primer/adhesive on the shear bond strength of orthodontic brackets. Am. J. Orthod. Dentofacial Orthop., St. Louis, v. 119, no. 6, p. 621-624, June 2001.

6. BISHARA, S. E.; VonWALD, L.; OLSEN, M. E.; LAFFOON, J. F. Effect of time on the shear bond strength of glass ionomer and composite orthodontic adhesives. Am. J. Orthod. Dentofacial Orthop., St. Louis, v. 116, no. 6, p. 616-620, Dec. 1999.

7. BUONOCORE, M. G. A simple method of increasing the adhesion of acrylic filling materials to enamel surfaces. J. Dent. Res., Chicago, v. 34, no. 6, p. 849-853, Dec. 1955.

8. CACCIAFESTA, V.; JOST-BRINKMANN, P.; SÜSSENBERGER, U.; MIETHKE, R. Effects of saliva and water contamination on the enamel shear bond strength of a light-cured glass ionomer cement. Am. J. Orthod. Dentofacial Orthop., St. Louis, v. 113, no. 4, p. 402-407, Apr. 1998.

9. DORMINEY, J. C.; DUNN, W. J.; TALOUMIS, L. J. Shear bond strength of orthodontic brackets bonded with a modified 1-step etchant-and-primer technique. Am. J. Orthod. Dentofacial Orthop., St. Louis, v. 124, no. 4, p. 410-413, Oct. 2003.

10. FERGUNSON, J. W.; READ, M. J. F.; WATTS, D. C. Bond strengths of an integral bracket base combination: an in vitro study. Eur. J. Orthod., Oxford, v. 6, no. 4, p. 267-276, Nov. 1984.

11. HOSEIN, I.; SHERRIFF, M.; IRLAND, A. J. Enamel loss during bonding, debonding, and cleanup with use of a self-etching primer. Am. J. Orthod. Dentofacial Orthop., St. Louis, v. 126, no. 6, p. 717-724, Dec. 2004.

12. KEIZER, S.; TEN CATE, J. M.; ARENDS, J. Direct bonding of orthodontic brackets. Am. J. Orthod., St. Louis, v. 69, no. 3, p. 318-327, Mar. 1976.

13. LANDIS, J. R.; KOCH, G. G. The measurement of observer agreement for categorical data. Biometrics, Alexandria, v. 33 no. 1, p. 159-174, Mar. 1977.

14. LOPEZ, J. I. Retentive shear strengths of various bonding attachment bases. Am. J. Orthod., St. Louis, v. 77, no. 6, p. 669-678, June 1980.

15. MATASA, C. G. Adhesion and its ten commandments. Am. J. Orthod., St. Louis, v. 95, no. 4, p. 355-356, Apr. 1989.

16. MILLET, D. T.; MCCABE, J. F. Orthodontic bonding with glass ionomer cement: a review. Eur. J. Orthod., Oxford, v. 18, no. 4, p. 385-399, Aug. 1996.

17. MIZRAHI, E.; SMITH, D. C. Direct cementation of orthodontic brackets to dental enamel. Br. Dent. J., London, v. 127, no. 8, p. 371-375, Oct. 1969.

18. NEWMAN, G. V.; NEWMAN, R. A.; SUN, B. I.; HA, J. L.; OZSOYLU, S. A. Adhesion promoters, their effect on the bond strength of metal brackets. Am. J. Orthod. Dentofacial Orthop., St. Louis, v. 108, p. 237-241, Sept. 1995.

19. NEWMAN, G. V.; SNYDER, W. H.; WILSON JÚNIOR, C. E. Acrylic adhesives for bonding attachments to tooth surfaces. Angle Orthod., Appleton, v. 38, no. 1, p. 12-18, Jan. 1968.
20. OLIVER, R. G.; HOWE, G. S. Scanning electron microscope appearance of enamel/composite/bracket areas using different methods of surface enamel treatment, composite mix and bracket bonding. Br. J. Orthod., London, v. 16, no. 1, p. 39-46, Feb. 1989

21. OSTERLE, L. J.; SHELLHART, W. C.; BELANGER, G. K. The use of bovine enamel in bonding studies. Am. J. Orthod. Dentofacial Orthop., St. Louis, v. 114, no. 5, p. 514-519. Nov. 1998.

22. OWENS JR., S. E.; MILLER, B. H. A comparison of shear bond strengths of three visible light: cured orthodontic adhesives. Angle Orthod., Appleton, v. 70, no. 5, p. 352-356, Oct. 2000

23. REGAN, D.; VAN NOORT, R. Bond strengths of two integral bracket-base combinations: an in vitro comparison with foilmesh. Eur. J. Orthod., Oxford, v. 11, no. 2, p. 144-153, May 1989.

24. RETIEF, D. H.; DENYS, F. R. Finishing of enamel surfaces after debonding of orthodontic attachments. Angle Orthod., Appleton, v. 49, no. 1, p. 1-10, Jan. 1979.

25. SADLER, J. F. A survey of some commercial adhesives: their possible application in clinical Orthodontics. Am. J. Orthod., St. Louis, v. 44, no. 1, p. 65-69, Jan. 1958.

26. SMITH, D. C.; MAIJER, R. Improvements in bracket base design. Am. J. Orthod., St. Louis, v. 83, no. 4, p. 277-281, Apr. 1983.

27. SMITH, N. R.; REYNOLDS, I. R. A comparison of three bracket bases an in vitro study. Br. J. Orthod., London, v. 18, no. 2, p. 29-35. Feb. 1991

28. WRIGHT, W. L.; POWERS, J. M. In vitro tensile bond strength of reconditioned brackets. Am. J. Orthod., St. Louis, v. 87, no. 3, p. 247-252, Mar. 1985

29. YAMADA, R.; HAYAKAWA, T.; KASAl, K. Effect of using self-etching primer for bonding orthodontic brackets. Angle Orthod., Appleton, v. 72, no. 6, p. 558-564, Dec. 2002.

30. ZACHRISSON, B. U.; SKOGAN, O.; HÖYMYHR, S. Enamel cracks in debonded, debanded, and orthodontically untreated teeth. Am. J. Orthod., St. Louis, v. 77, no. 3, p. 307-319, Mar. 1980.
Endereço para correspondência

Lilian Maria Brisque Pignatta

Rua Oscar Rodrigues Alves, 625, ap. 102

CEP: 16.015-030 - Vila Mendonça - Araçatuba/SP

E-mail: lipignatta@hotmail.com 